\title{
Application of Back-Propagation Neural Network in Horoscope Prediction
}

\author{
Usha Sharma \\ M Phil Scholar, Computer \\ Science, \\ A P S University Reewa, M.P.
}

\author{
Sanjeev Karmakar \\ Associate Professor, Computer \\ Applications \\ Bhilai Institute of Technology, \\ Durg, Bhilai House, 491001, \\ Chhattisgarh, India
}

\author{
Navita Shrivastava \\ Professor, Computer Science \\ A P S University Reewa, M.P
}

\begin{abstract}
In this study a back-propagation neural network model is designed and its parameters are optimized for prediction of horoscope to identify a person type. Person type is a dynamic system based on the planet system. It is found that the backpropagation neural network is capable to predict the person type by learning planet dataset. The model is trained up to model error (i.e., mean square error) 1.2864E-04 and performs excellent during training and testing process.
\end{abstract}

\section{Keywords}

Neural Network, Prediction, Back-propagation, Horoscope

\section{INTRODUCTION}

System is defined as $y=f\left(x_{1}, x_{2}, x_{3} \ldots, w_{1}, w_{2}, w_{3} \ldots\right)$ can be treated as non-linear dynamic system where different values of ' $y$ ' are dependent to different values of independent variables $x_{1}, x_{2}, x_{3}$. The $w_{1}, w_{2}, w_{3} \ldots$ are the weights are to be adjusted to predict ' $y$ ' from inputted values of $x_{1}, x_{2}, x_{3}$. In other word $x_{1}, x_{2}, x_{3}$ are called predictors of the system $y$. here, $\mathrm{y}$ is dynamic and non-linear and depending on values of $x_{1}, x_{2}, x_{3}$. Neural network and its training algorithm are basically used to define such system by adjustment of weights $w_{1}, w_{2}, w_{3}$ during training process. These weights are called trainable weights. In each epoch (iterations) the neural network may minimize the error between actual $y$ 's and its predicted values by adjustment of $w_{1}, w_{2}, w_{3}$ called training process. After training new values of $x_{1}, x_{2}, x_{3}$ may possibly be given to observe predicted value of y called validation or testing. It observed that weather datasets, stock datasets, financial datasets etc are dynamic system always depending on their predictors (independent variables). And neural network may identify the relationship between depending and independent variables. Thus in recent year many contributors are utilizing neural network for prediction of such system. It is observed that the Back-propagation neural network is sufficiently suitable for prediction of dynamic system as mentioned in the following Table 1, wherein, 17 different models have been depicted with their contributors. Thus in this study back-propagation neural network is applied for horoscope prediction as well.

Table 1. Neural network models for non-linear dynamic system

\begin{tabular}{|l|l|l|r|l|}
\hline No. & Contributor & Application & Year & ANN Model \\
\hline 1 & $\begin{array}{l}\text { Tarsauliya } \\
\text { et al., }\end{array}$ & $\begin{array}{l}\text { Financial } \\
\text { forecasting }\end{array}$ & 2010 & $\begin{array}{l}\text { Back- } \\
\text { propagation } \\
\text { and redial } \\
\text { basis } \\
\text { function }\end{array}$ \\
\hline
\end{tabular}

\begin{tabular}{|c|c|c|c|c|}
\hline 2 & $\begin{array}{l}\text { Peralta et } \\
\text { al., }\end{array}$ & $\begin{array}{l}\text { Time series } \\
\text { forecasting }\end{array}$ & 2010 & $\begin{array}{l}\text { Back- } \\
\text { propagation } \\
\text { and genetic } \\
\text { algorithm }\end{array}$ \\
\hline 3 & $\begin{array}{l}\text { Akintola et } \\
\text { al., }\end{array}$ & $\begin{array}{l}\text { Stock market } \\
\text { forecasting }\end{array}$ & 2011 & $\begin{array}{l}\text { Back } \\
\text { propagation }\end{array}$ \\
\hline 4 & $\begin{array}{l}\text { Juan José } \\
\text { Montaño } \\
\text { Moreno et } \\
\text { al., }\end{array}$ & $\begin{array}{l}\text { Time series } \\
\text { forecasting }\end{array}$ & 2011 & $\begin{array}{l}\text { Multilayer } \\
\text { Perceptron, } \\
\text { Radial Base } \\
\text { Function, } \\
\text { Generalized } \\
\text { Regression } \\
\text { ANN, } \\
\text { Recurrent } \\
\text { Neural } \\
\text { Network. }\end{array}$ \\
\hline 5 & Khan et al, & $\begin{array}{l}\text { Share Market } \\
\text { forecasting }\end{array}$ & 2011 & $\begin{array}{l}\text { Back- } \\
\text { propagation }\end{array}$ \\
\hline 6 & Vrabe et al & $\begin{array}{l}\text { Prediction of } \\
\text { surface } \\
\text { roughness }\end{array}$ & 2012 & $\begin{array}{l}\text { Back- } \\
\text { propagation }\end{array}$ \\
\hline 7 & Devi et al., & $\begin{array}{l}\text { Temperature } \\
\text { forecasting }\end{array}$ & 2012 & $\begin{array}{l}\text { Back- } \\
\text { propagation }\end{array}$ \\
\hline 8 & $\begin{array}{l}\text { Donate et } \\
\text { al., }\end{array}$ & $\begin{array}{l}\text { Time series } \\
\text { forecasting }\end{array}$ & 2013 & $\begin{array}{l}\text { Back- } \\
\text { propagation } \\
\text { with genetic } \\
\text { algorithm }\end{array}$ \\
\hline 9 & Sa et al., & $\begin{array}{l}\text { Forest } \\
\text { forecasting }\end{array}$ & 2013 & $\begin{array}{l}\text { Multilayer } \\
\text { perceptron }\end{array}$ \\
\hline 10 & Vieira & $\begin{array}{l}\text { prices } \\
\text { movements of } \\
\text { oil and gas } \\
\text { companies } \\
\text { listed in stock } \\
\text { exchanges }\end{array}$ & 2013 & $\begin{array}{l}\text { Multilayer } \\
\text { Perceptron } \\
\text { models with } \\
\text { logistic } \\
\text { activation } \\
\text { functions }\end{array}$ \\
\hline 11 & $\begin{array}{l}\text { Tamizharasi } \\
\text { et al., }\end{array}$ & $\begin{array}{l}\text { Prediction the } \\
\text { long range } \\
\text { energy } \\
\text { consumption } \\
\text { for a country }\end{array}$ & 2014 & $\begin{array}{l}\text { Back- } \\
\text { propagation }\end{array}$ \\
\hline 12 & Malik et al., & $\begin{array}{l}\text { Weather } \\
\text { forecasting }\end{array}$ & 2014 & $\begin{array}{l}\text { Back- } \\
\text { propagation }\end{array}$ \\
\hline 13 & Patel et al., & $\begin{array}{l}\text { Stock price } \\
\text { prediction }\end{array}$ & 2014 & $\begin{array}{l}\text { Back- } \\
\text { propagation }\end{array}$ \\
\hline 14 & Rao et al., & $\begin{array}{l}\text { Stock } \\
\text { forecasting }\end{array}$ & 2014 & $\begin{array}{l}\text { Back- } \\
\text { propagation }\end{array}$ \\
\hline 15 & Kuna, & $\begin{array}{l}\text { Time series } \\
\text { forecasting }\end{array}$ & 2015 & $\begin{array}{l}\text { Recurrent } \\
\text { neural } \\
\text { networks }\end{array}$ \\
\hline
\end{tabular}




\begin{tabular}{|l|l|l|l|l|}
\hline 16 & $\begin{array}{l}\text { Enyindah et } \\
\text { al., }\end{array}$ & $\begin{array}{l}\text { Financial } \\
\text { forecasting }\end{array}$ & 2016 & $\begin{array}{l}\text { Back- } \\
\text { propagation }\end{array}$ \\
\hline 17 & Shah et al., & $\begin{array}{l}\text { Stock market } \\
\text { prediction }\end{array}$ & 2016 & $\begin{array}{l}\text { Back- } \\
\text { propagation, } \\
\text { Multilayer } \\
\text { perceptron, }\end{array}$ \\
& & $\begin{array}{l}\text { Redial basis } \\
\text { function }\end{array}$ \\
\hline
\end{tabular}

A horoscope prediction system can be defined as

Type $=f($ Asce, Sun, Moon, Mars, Mercury,

Jupiter, Venus, Saturn, Rahu, Ketu,

Urenus, Nep, Pluto)

Here, Type may be Sportsman (2), Lawyer (4), Politician (5), Actor (8), scientist (8), astrologer (9), singer (6). Asce, Sun, Moon, Mars, Mercury, Jupiter, Venus, Saturn, Rahu, Ketu, Urenus, Neptune, Pluto are the predictor are to be inputted to the system to observed type as target.
The paper has been constructed with different sections. Section 2 used to describe dataset of horoscope, In section 3, the backpropagation neural network architecture is optimized to establish relationship between independent variables Asce, Sun, Moon, Mars, Mercury, Jupiter, Venus, Saturn, Rahu, Ketu, Urenus, Neptune, Pluto with the type. Section 4 represented for performance of the neural network, Result and discussion is explained in section 5, and concluded the paper in section 6 .

\section{DATA \& PRE-PROCESSING}

1200 record of different types and their corresponding planet values (i.e., Asce, Sun, Moon, Mars, Mercury, Jupiter, Venus, Saturn, Rahu, Ketu, Urenus, Neptune, Pluto) are used in this study. Out of 1200, 1993 records of different types (i.e., Sportsman (2), Lawyer (4), Politician (5), Actor (8), scientist (8), astrologer (9), singer (6)) and their planets are used for neural network system development (i.e., training) and one record of each type are used for testing as depicted in the following Table 2. Dataset are normalized within the closed interval [l 1 1] for neural network modelling.

\begin{tabular}{|l|l|l|l|l|l|l|l|l|l|l|l|l|l|}
\hline Asc & Sun & Moo & Mars & Mer & Jup & Ven & Sat & Rah & Ket & Ure & Nep & Plu & Type \\
\hline 1 & 1 & 9 & 3 & 1 & 9 & 1 & 3 & 9 & 3 & 3 & 7 & 6 & 2 \\
\hline 1 & 5 & 11 & 6 & 5 & 8 & 7 & 10 & 12 & 6 & 2 & 4 & 3 & 4 \\
\hline 4 & 6 & 8 & 6 & 6 & 4 & 6 & 2 & 5 & 11 & 2 & 6 & 4 & 5 \\
\hline 8 & 9 & 12 & 5 & 9 & 9 & 8 & 9 & 8 & 2 & 8 & 3 & 2 & 8 \\
\hline 5 & 2 & 4 & 5 & 2 & 3 & 3 & 5 & 6 & 12 & 7 & 8 & 6 & 3 \\
\hline 3 & 8 & 8 & 7 & 9 & 5 & 9 & 8 & 8 & 2 & 4 & 7 & 5 & 9 \\
\hline 9 & 10 & 2 & 9 & 9 & 9 & 11 & 2 & 12 & 6 & 10 & 4 & 3 & 6 \\
\hline
\end{tabular}

\section{NEURAL NETWORK MODELLING}

The structural design of Neural Network includes its primary parameters i.e., Number of input vectors in input layer (n), Number of neurons in hidden layers (p), Learning rate $(\alpha)$, Momentum factor $(\mu)$, and sets of biases and learning weights (i.e., w and v) as shown in following Fig. 1. It is known that, these parameters are dynamic based on input and targeted variables of the network. The identification of optimum values of parameters like $n, p, \alpha$, and $\mu$ is an effort. at the same time as it is known that, without optimization of these parameters, might be reason of the unfortunate presentation. In this section the selection of these parameters and their optimization are discussed in this case. The architecture is shown.

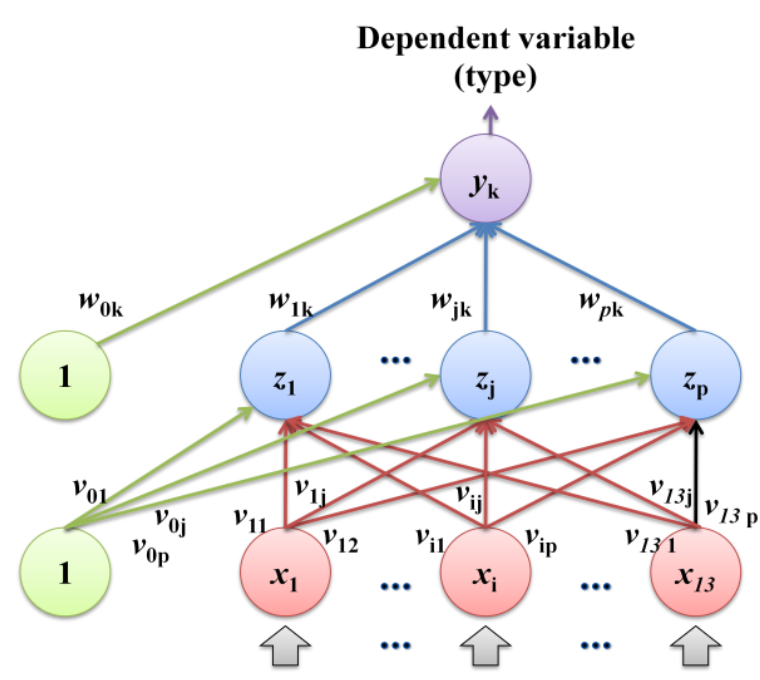

(Independent variables)

Asce, Sun, Moon, Mars, Mercury, Jupiter, Venus, Saturn, Rahu, Ketu, Urenus, Neptune, Pluto

Fig. 1. Architecture of Neural Network for Spatial Interpolation

\subsection{Optimization of Parameters}

3.1.1 Number of input vectors in input layer (n) Input of the model are 13 in this case i.e., Asce, Sun, Moon, Mars, Mercury, Jupiter, Venus, Saturn, Rahu, Ketu, Urenus, Neptune, Pluto. Look at the Fig. 1. In this case $n=13$. 


\subsubsection{Number of output neurons (y)}

Single output neuron is used to observe targeted value i.e., type (i.e., Sportsman (2), Lawyer (4), Politician (5), Actor (8), scientist (8), astrologer (9), singer (6))

\subsubsection{Number of hidden layer}

For nearly all problems, one hidden layer is enough. Using two hidden layers hardly ever advances the model, and it may introduce a greater hazard of converging to a local minima. There is no theoretical reason for using more than two hidden layers.

\subsubsection{Number of neurons in hidden layers $(p)$}

To obtain optimum value of ' $p$ ' experiment have been accomplished. Experiment is done with initial weights and biases and with 100 epochs. The minimization of error (i.e., mean square error 'MSE') is observed and tried to identify the minimum mean square error (MSE) with corresponding parameter ' $p$ '. The minimization of error during training period of the system with their corresponding ' $p$ ' is given in the following Table 2 and Fig 2. Wherein, it is clear that 30 neurons is optimum in this dataset for which the network error MSE $=3.3237443368085606 \mathrm{E}-4$ is less therefore $\mathrm{p}=30$ is selected for this study.

Table.2. MSE corresponding to the number of neurons in hidden layer

\begin{tabular}{|c|l|}
\hline $\begin{array}{c}\text { Number of neurons } \\
\text { in hidden layer }(\boldsymbol{p})\end{array}$ & MSE \\
\hline 2 & 0.001638729377750392 \\
\hline 3 & 0.001638729377750392 \\
\hline 4 & 0.001115547257976215 \\
\hline 5 & 0.001010576885637086 \\
\hline 6 & $8.835130957905274 \mathrm{E}-4$ \\
\hline 7 & $8.075992623893731 \mathrm{E}-4$ \\
\hline 8 & $7.759794687476993 \mathrm{E}-4$ \\
\hline
\end{tabular}

\begin{tabular}{|c|c|}
\hline 9 & $7.133125805921601 \mathrm{E}-4$ \\
\hline 10 & $6.694183869879488 \mathrm{E}-4$ \\
\hline 11 & $6.218868396468241 \mathrm{E}-4$ \\
\hline 12 & $5.920673410781053 \mathrm{E}-4$ \\
\hline 13 & $5.583996878601329 \mathrm{E}-4$ \\
\hline 14 & 5.419979904455619E-4 \\
\hline 15 & $5.015120082000626 \mathrm{E}-4$ \\
\hline 16 & $4.888934797089644 \mathrm{E}-4$ \\
\hline 17 & $4.637275279312396 \mathrm{E}-4$ \\
\hline 18 & $4.381587423248476 \mathrm{E}-4$ \\
\hline 19 & $\begin{array}{c}4.3605970407206533 \mathrm{E}- \\
4\end{array}$ \\
\hline 20 & $4.226594474728315 \mathrm{E}-4$ \\
\hline 21 & $4.067383031635331 \mathrm{E}-4$ \\
\hline 22 & $\begin{array}{l}3.9361198686128815 \mathrm{E}- \\
4\end{array}$ \\
\hline 23 & $\begin{array}{c}3.8158927065329415 \mathrm{E}- \\
4\end{array}$ \\
\hline 24 & $3.78634287524848 \mathrm{E}-4$ \\
\hline 25 & 3.605971241822392E- \\
\hline 26 & 0.28026419620770426 \\
\hline 27 & 0.280256517557533 \\
\hline 28 & $3.429787497471353 \mathrm{E}-4$ \\
\hline 29 & 0.28026627908467705 \\
\hline 30 & $\begin{array}{c}3.3237443368085606 \mathrm{E}- \\
4\end{array}$ \\
\hline
\end{tabular}

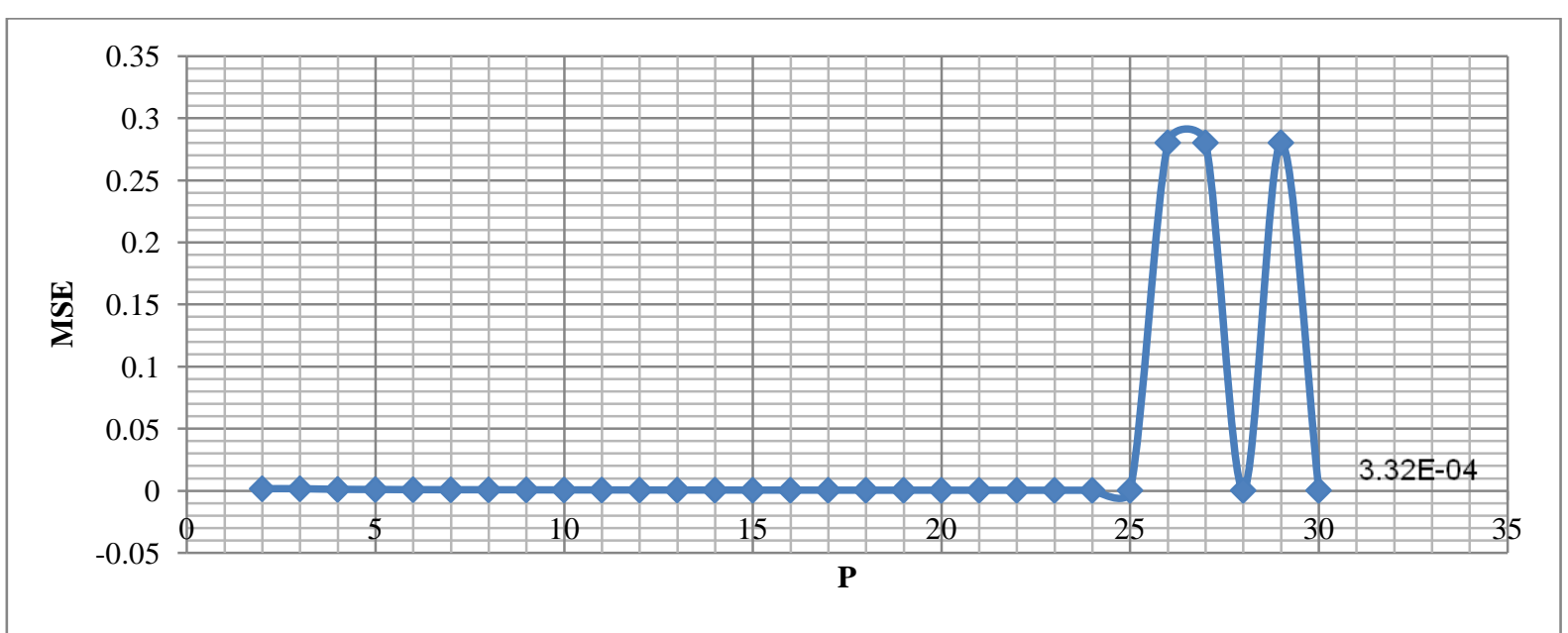

Fig. 2. MSE Corresponding to the Number of Neurons in Hidden Layer 


\subsubsection{Learning rate $(\alpha)$}

This parameter is highly significance for speeding up the training process and minimization of MSE by upgrading the trainable weights and biases. It is found that, a high ' $\alpha$ ' leads to rapid learning but the weights may oscillate, while a lower value of $\alpha$ leads to slower learning process. Identification of an suitable value of $\alpha$ preserving a higher learning process needs special attention of the researchers in this area. It is tried to identify most favourable value of ' $\alpha$ ' through the experiments where value of ' $\alpha$ ' is considered in the close interval [0 1]. The values of ' $\alpha$ ' and corresponding MSE through 100 epochs and $p$ $=30$ of learning is given in the following Fig 2 and Table 2. It is clear that $\alpha=0.62$ is optimum.

Table 2. MSE Corresponding to learning rate ( $\alpha)$

\begin{tabular}{|l|l|l|l|l|l|l|l|l|l|}
\hline $\begin{array}{l}\text { Momentum } \\
\text { factor }\end{array}$ & 0.1 & 0.2 & 0.3 & 0.4 & 0.5 & 0.6 & 0.6 & 0.8 & 0.9 \\
\hline 1 & 0.280 & 0.280 & $3.14 \mathrm{E}-4$ & $2.34 \mathrm{E}-4$ & 0.28 & $2.32 \mathrm{E}-4$ & $2.5 \mathrm{E}-4$ & $2.58 \mathrm{E}-4$ & $2.7 \mathrm{E}-4$ \\
\hline $\begin{array}{l}\text { Recommend ed } \\
\text { Learning Facto }\end{array}$ & 0.61 & $\mathbf{0 . 6 2}$ & 0.63 & 0.64 & 0.65 & 0.66 & 0.67 & 0.68 & 0.69 \\
\hline $\mathbf{0 . 6}$ & 0.28 & $\begin{array}{l}2.32 \mathrm{E}- \\
04\end{array}$ & $\begin{array}{l}2.328 \mathrm{E}- \\
04\end{array}$ & 0.28 & $2.34 \mathrm{E}-4$ & 0.29 & $2.32 \mathrm{E}-4$ & $2.33 \mathrm{E}-4$ & 0.28 \\
\hline
\end{tabular}

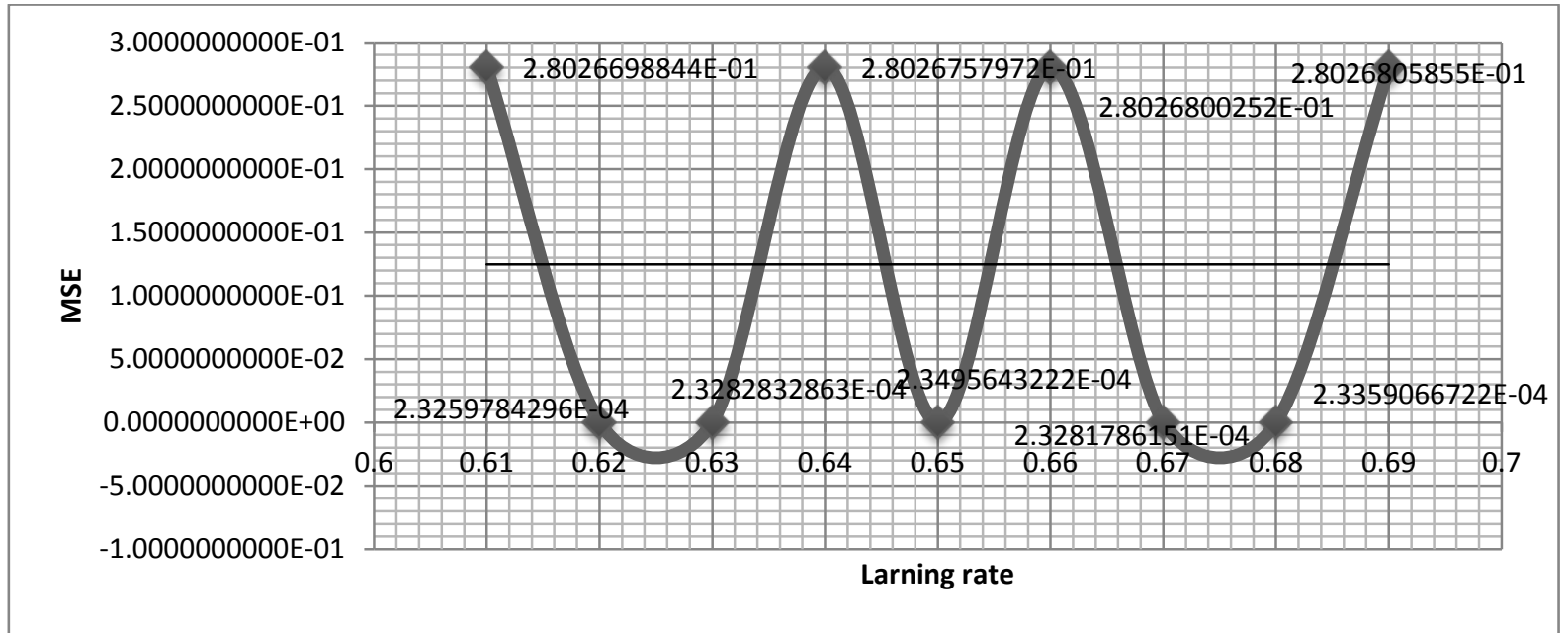

Fig. 3. MSE Corresponding to learning rate ( $\alpha)$

\subsubsection{Momentum factor $(\mu)$}

The main purpose of the momentum factor $(\mu)$ is to accelerate the convergence of error during the training period in the equations (Karmakar et al., 2014). It is very important to know its optimum value between close interval [ $\left[\begin{array}{ll}0 & 1\end{array}\right]$. The values of ' $\mu$ ' and corresponding MSE's are obtained by 100 epochs of learning $\alpha=0.62$ and $p=30$ is given in the following Fig 4 and Table 3 . It is clear that $\mu=0.96$ is optimum.

Table 3. MSE Corresponding Momentum factor $(\mu)$

\begin{tabular}{|l|l|l|l|l|l|l|l|l|l|}
\hline Learning rate & 0.1 & 0.2 & 0.3 & 0.4 & 0.5 & 0.6 & 0.6 & 0.8 & 0.9 \\
\hline 0.62 & 0.28 & 0.28 & 0.28 & 0.28 & $3.04 \mathrm{E}-4$ & 0.28 & $2.57 \mathrm{E}-4$ & $2.42 \mathrm{E}-4$ & $2.39 \mathrm{E}-4$ \\
\hline $\begin{array}{l}\text { Recommend } \\
\text { momentum factor }\end{array}$ & 0.91 & 0.92 & 0.93 & 0.94 & 0.95 & 0.96 & 0.97 & 0.98 & 0.99 \\
\hline $\mathbf{0 . 6}$ & $\begin{array}{l}2.36 \mathrm{E}- \\
4\end{array}$ & $\begin{array}{l}2.34 \mathrm{E}- \\
4\end{array}$ & 0.28 & $\begin{array}{l}2.34 \mathrm{E}- \\
4\end{array}$ & $2.37 \mathrm{E}-4$ & $\begin{array}{l}\mathbf{2 . 3 3 E} \\
\mathbf{- 4}\end{array}$ & $2.34 \mathrm{E}-4$ & $2.33 \mathrm{E}-4$ & 0.28 \\
\hline
\end{tabular}




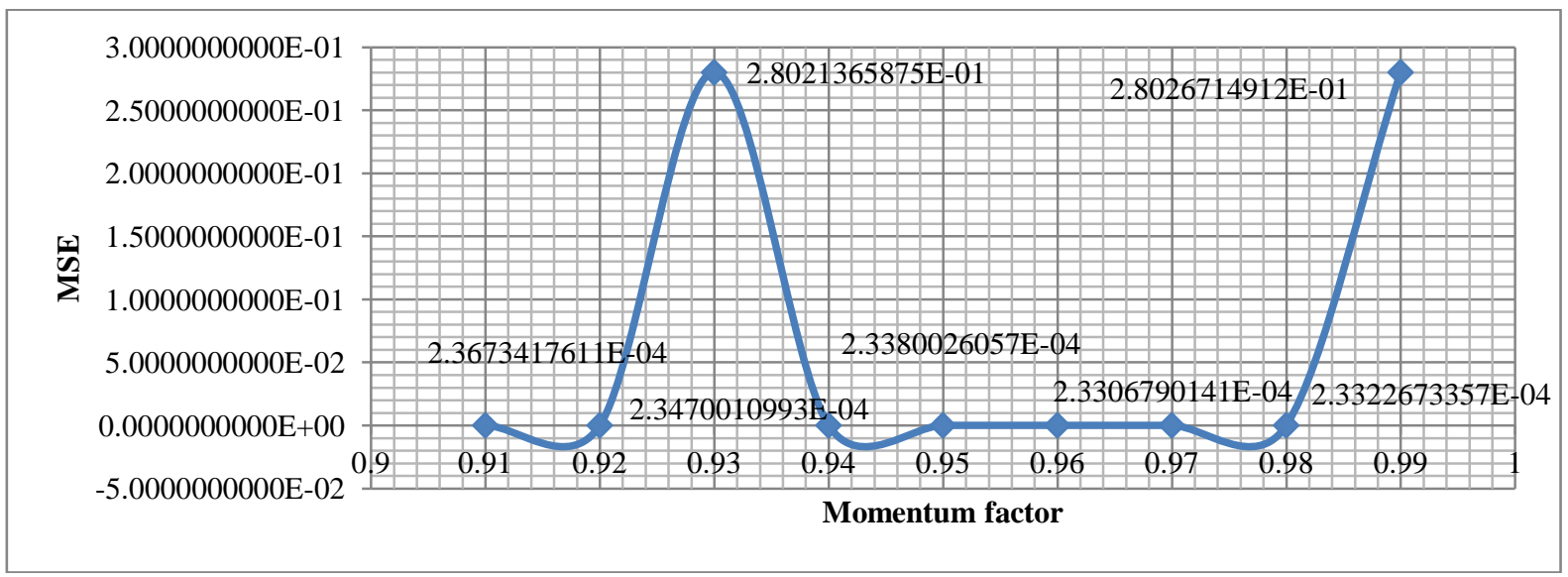

Fig. 4. MSE Corresponding Momentum factor $(\mu)$

\section{TRAINING}

As per the discussion of section 3, it is found that parameters of Neural Network based on the experiment 5 are extremely suitable wherein, $n=13, p=30, \alpha=0.62, \mu=0.96$ is optimum. The datasets of 1200 records are divided into two subset i.e., training and testing period. 1193 records are used for the training process and out of 1200 stations 7 records are randomly selected and used for the testing process. The initial weight and biases are selected randomly selected from close interval [0 1]. Then In each epoch the model minimizes MSE between actual targeted value and model predicted values as depicted in the following Fig.5. The training process minimized the model error MSE between actual and predicted values upto $\mathrm{MSE}=1.2864 \mathrm{E}-04$

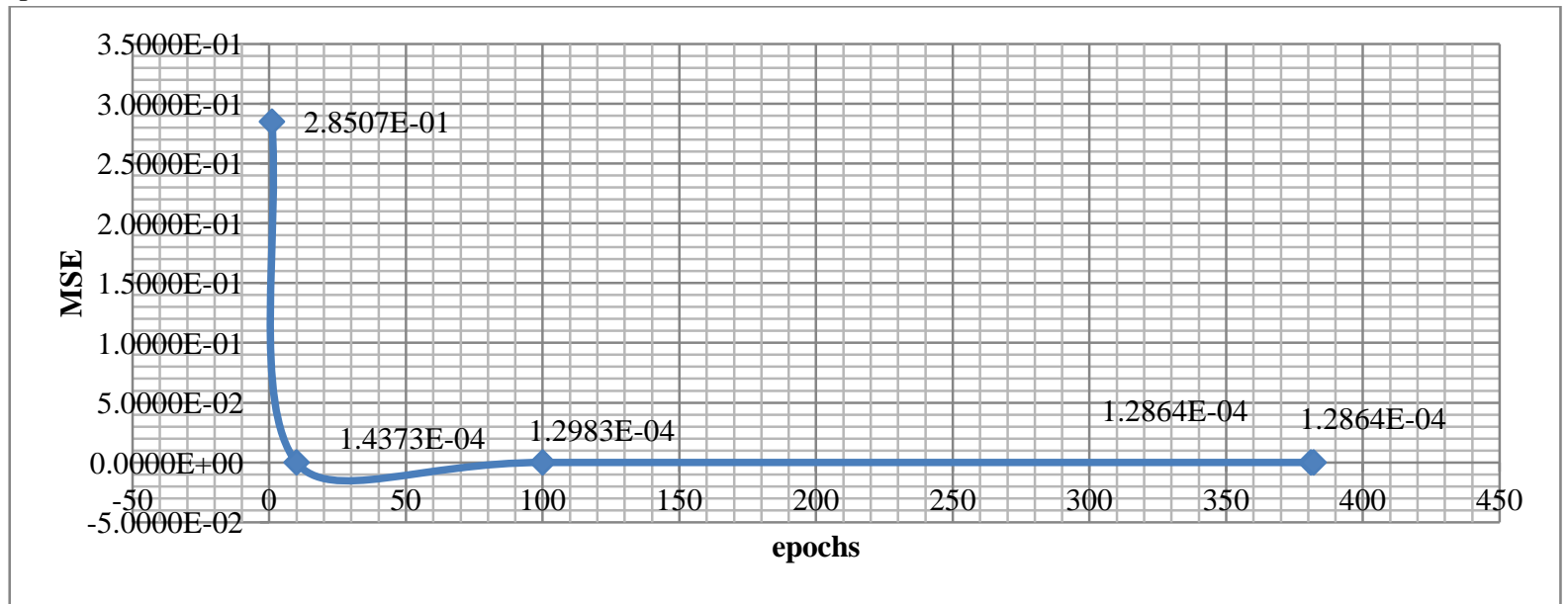

Fig. 5. Minimization of error during training process

\subsection{Trained model}

At $\mathrm{MSE}_{\mathrm{G}}=4.76 \mathrm{E}-04$ might be considered as optimum and model might be assumed as fully trained. In this point the model has shown maximum performance. During the training process the trainable weights and biases are updated. At global minima $\mathrm{MSE}_{\mathrm{G}}$ the updated weights and biases are shown in the following Table. In point of fact, it might be considered as a trained model and it is ready to suggest future values as target by inputted new independent values. In our case, now geo- coordinates (i.e., latitude, longitude, and altitude) unknown station may be inputted to interpolate the mean rainfall.

\subsection{Performance in training}

The performance of the model is training period is depicted in the following Fig 6. It is also visible that the absolute deviation between actual and predicted values are exceptionally small as depicted in the Fig. 7 As a result the model is accepted. 


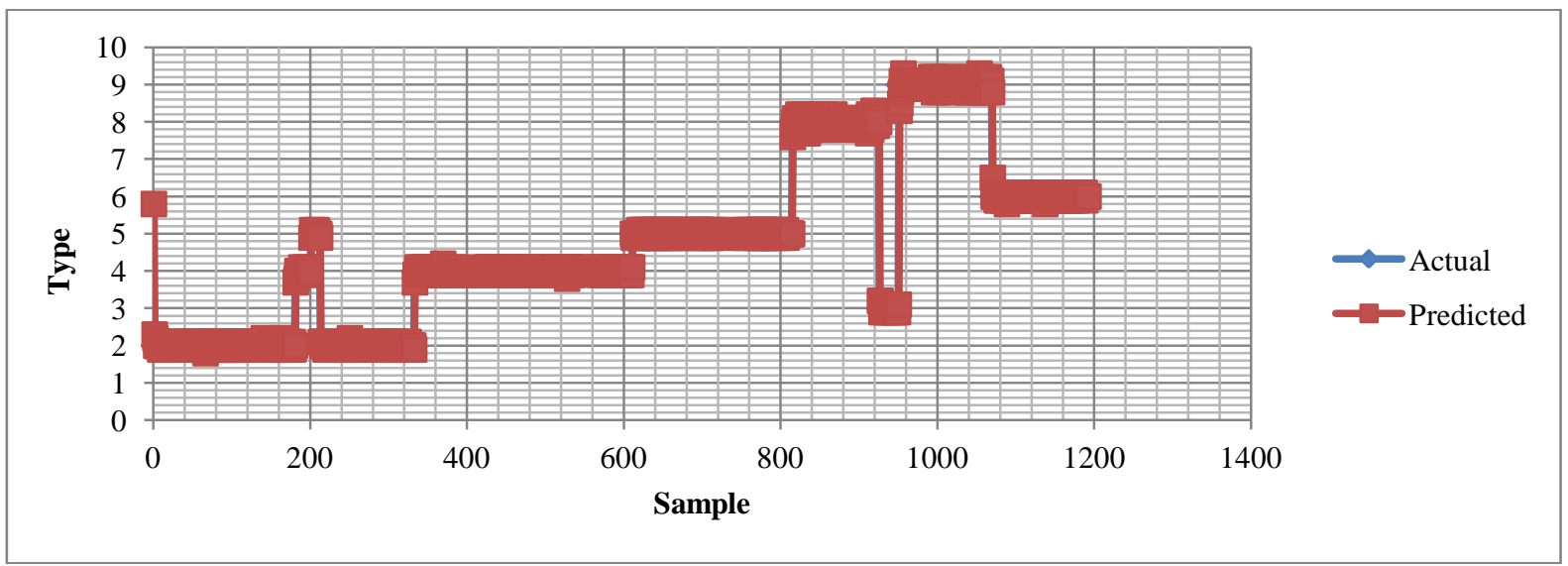

Fig. 6. Performance in Training Process

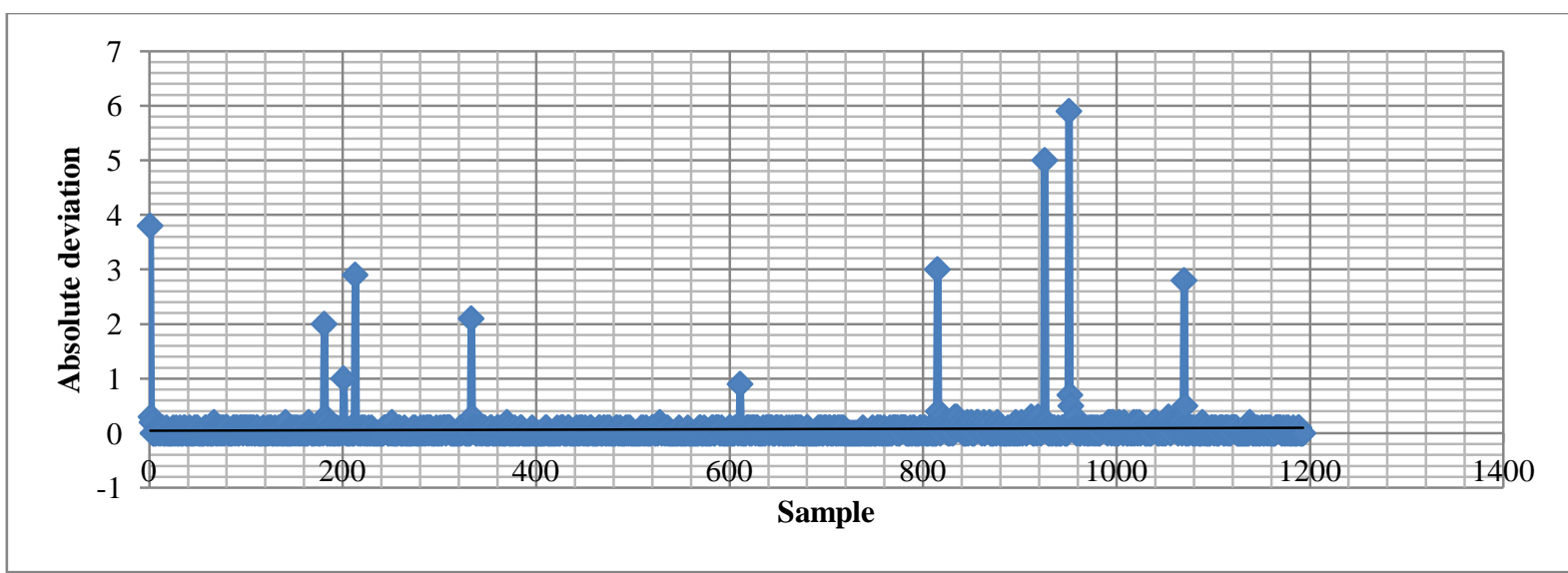

Fig. 7. Absolute Deviation between Actual and Predicted Values

\section{TESTING}

The performance of the model in training period is depicted in the following Table 8 and Fig 8 . It is also visible that the mean absolute deviation is exceptionally small(Fig 9). Thus model is.

Table. 8. Performance in Testing Process

\begin{tabular}{|r|r|r|r|}
\hline No & Actual & Predicted & Deviation \\
\hline 1 & 2 & 1.9 & 0.1 \\
\hline
\end{tabular}

\begin{tabular}{|r|r|r|r|}
\hline 6 & 4 & 4 & 0 \\
\hline 8 & 5 & 4.8 & 0.2 \\
\hline 14 & 8 & 7.6 & 0.4 \\
\hline 19 & 3 & 3.1 & 0.1 \\
\hline 22 & 9 & 9.2 & 0.2 \\
\hline 27 & 6 & 6.1 & 0.1 \\
\hline
\end{tabular}

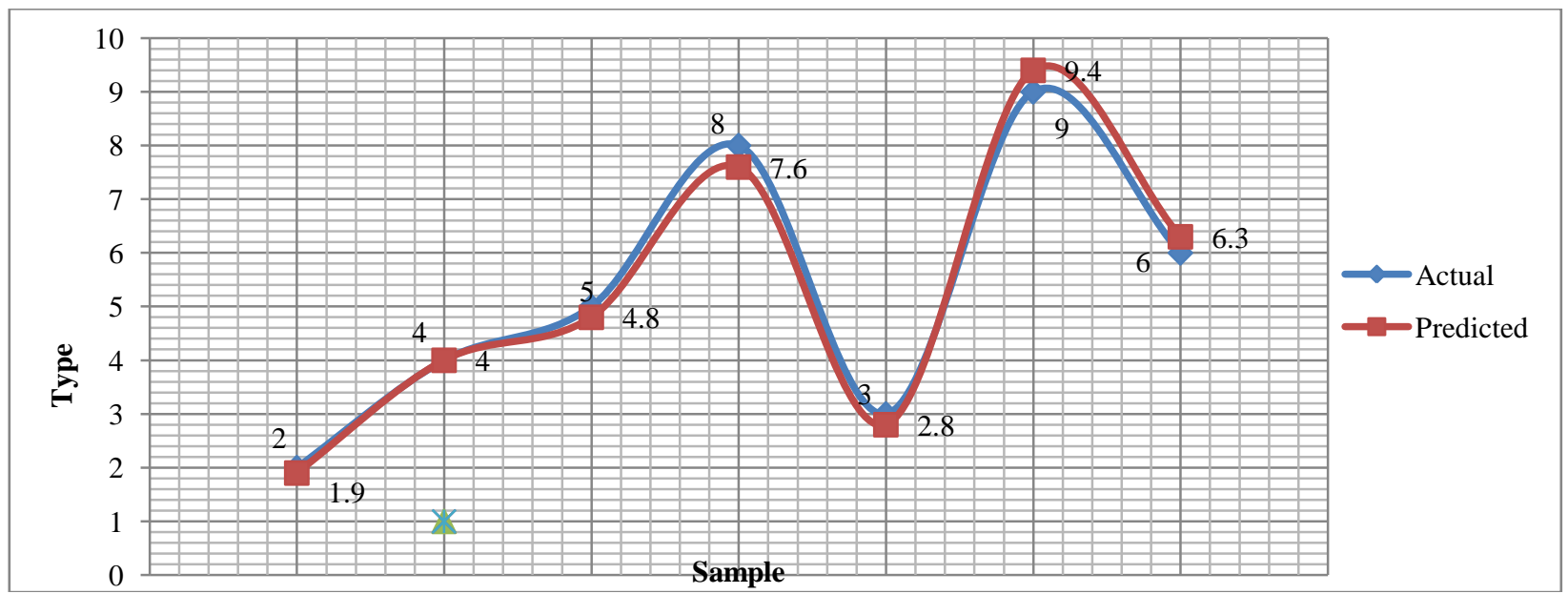

Fig. 8. Performance in Training Process 


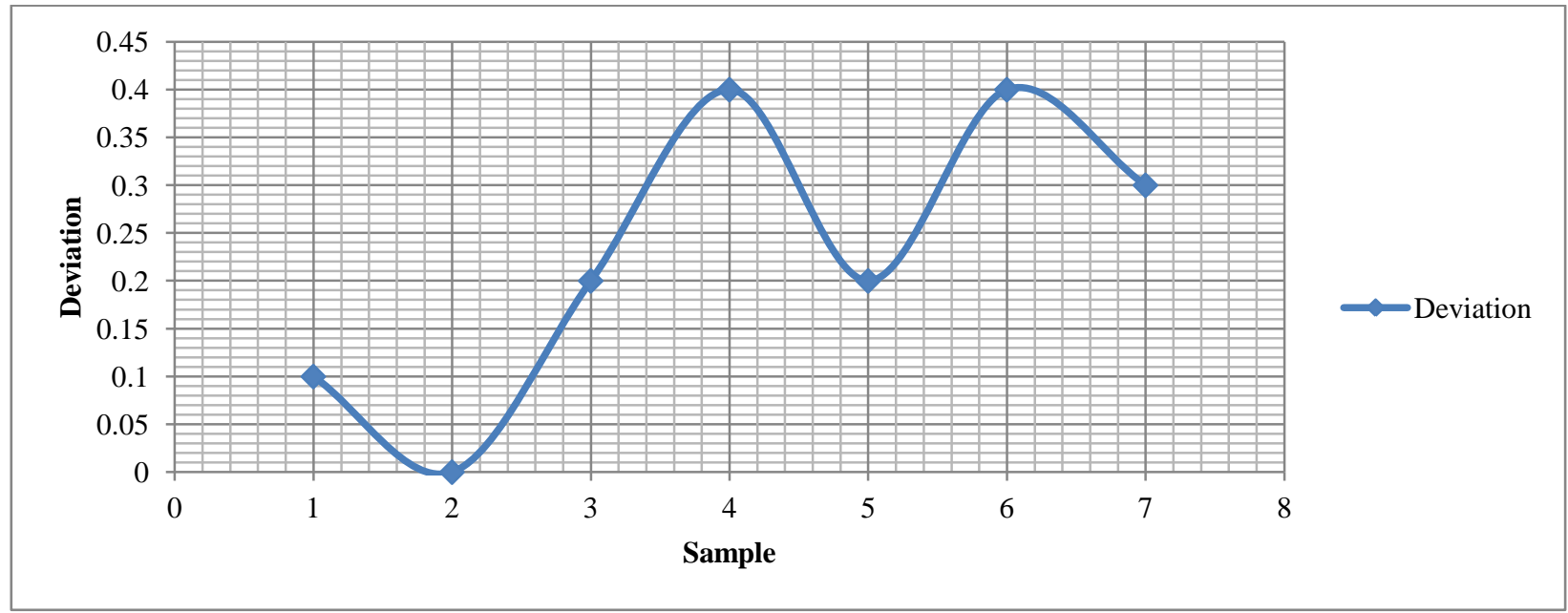

Fig 9. Absolute Deviation between Actual and Predicted Values in Testing Period

\section{RESULTS AND DISCUSSIONS}

In this study Neural Network model was developed for prediction of horoscope in which, 1200 records of different horoscope type were under study. Out of 1200 record type, 1193 records are selected for training and 7 records are selected randomly for testing of the model and following significance results have been found the Identification of architecture of neural network for prediction is complex and some time is sequential nervousness and also absolutely vibrant based on the inputted and independent parameters. In this study we observed that back-propagation neural network is suitable however its architecture is optimized as $n=13, p=30, \alpha=0.62, \mu=0.96$. And found the optimum result with less deviation between actual and predicted values. Model is trained up to the minimal model error MSE $=1.2864 \mathrm{E}-04$. Finally it is also observed that the model is performed well in testing period with minimum absolute deviation between actual and predicted values. Thus as a result it is found that neural network is suitable for horoscope prediction like other dynamic system as well.

\section{CONCLUSIONS}

It is concluded that, neural network is significance for constructing a relationship between planet dataset and horoscope type of a person. However, it is necessity that the neural network must be properly designed and. The proper model in this case have been found e.g., in this case, $n=13$, $p=30, \alpha=0.62, \mu=0.96$. The training process is minimized model error up to MSE $=1.2864 \mathrm{E}-04$ that were achieved by 281 epoch only and produced excellent result. Finally it is concluded that the back-propagation neural network is a appropriate tool for horoscope prediction as well.

\section{REFERENCES}

[1] Tarsauliya, A., Kant, S., Kala, R., Tiwari, R., Shukla, A., 2010, "Analysis of Artificial Neural Network for Financial Time Series Forecasting", International Journal of Computer Applications, 9 (5), 24-30.

[2] Peralta, J., Xiaodong Li, Gutierrez, G., and Sanchis, A., Time series forecasting by evolving artificial neural networks using genetic algorithms and differential evolution, IEEE World Congress on Computational Intelligence July, 18-23, 2010. CCIB, Barcelona, Spain.

[3] Akintola, K.G., Alese ,B.K, Thomson, A.F.,2011, Time Series forecasting with neural network, IJRRAS, 9(3),
[4] Juan José Montaño Moreno, Alfonso Palmer Pol and Pilar Muñoz Gracia, 2011, Artificial neural networks applied to forecasting time series, Psicothema, 23, (2), pp. 322-329.

[5] Khan, Z, H., Alin, T.S., Hussain, A., 2011, Price Prediction of Share Market using Artificial Neural Network (ANN), J. Computer 22(2).

[6] Vrabe,M., Mankovaa, I., Benoa, J., Tuharskýa,J., 2012 Surface roughness prediction using artificial neural networks when drilling Udimet 720, Procedia Engineering $48693-700$.

[7] Devi, J. , Reddy, B.S.P., Kumar, K.V., Reddy, B.M., Nayak, N.R., 2012, ANN Approach for Weather Prediction using Back Propagation, J. Engineering Trends and Technology-3(1).

[8] Donate, J.P., Li,X., 2013, Time series forecasting by evolving artificial neural networks with genetic algorithms, differential evolution and estimation of distribution algorithm, Neural Comput \& Applic 22 pp.,11-20.

[9] Sa, Y., and Bouroumi, A., Prediction of Forest Fires Using Artificial Neural Networks, 2013, Applied Mathematical Sciences, 7(6), 271 - 286

[10] Vieira, C. 2013 Forecasting Financial Marketing, Thesis, School of echo, and management, Lisbon,.

[11] Tamizharasi, G. Kathiresan, S. Sreenivasan, K.S., 2014, Energy Forecasting using Artificial Neural Networks, $J$. Advanced Research in Electrical, Electronics and Instrumentation Engineering 3(3).

[12] Malik, P., Singh, S., Arora, B., 2014 An Effective Weather Forecasting Using Neural Network, J. Emerging Engineering Research and Technology 2(2), p. 209-212.

[13] Patel, M.B. , Yalamalle, S.R , 2014, Stock Price Prediction Using Artificial Neural Network J. Innovative Research in Science, Engineering and Technology, 3(6).

[14] Rao, A.N., Rao, K.E. , 2014, Estimize Bull speed using Back propagation J. Modern Engineering Research (IJMER), 4(11).

[15] Kuna, K, Time Series Prediction Using Neural Networks , Masaryk Univ., Faculty of Informatics, Thesis, Brno, 
International Journal of Applied Information Systems (IJAIS) - ISSN : 2249-0868

Foundation of Computer Science FCS, New York, USA

Volume 11 - No. 2, July 2016 - www.ijais.org

Spring 2015.

[16] Enyindah, P. Uzochukwu, C , 2016, A Neural Network Approach to Financial Forecasting , J. Computer Applications 135(8),

[17] Shah, V.V., Mirani, S.J. Nanavati, Y.V., Narayanan, V., Pereira. S.I., Stock Market Prediction using
NeuralNetworks, 2016, J. Soft Computing and Engineering (IJSCE) 6 (1).

[18] Karmakar.S.,Shrivastava.G., and Kowar.M.K., 2014, Impact of Learning Rate and Momentum Factor in the Performance of Back-Propagation Neural Network to Identify Internal Dynamics of Chaotic Motion, Kuwait J.Sci,41(2),151-174 